\title{
A luta por Betim - MG
}

\author{
Jurutan Alves da Silva ${ }^{1}$
}

- Enviado em 15/09/2016

- Aprovado em 18/09/2016
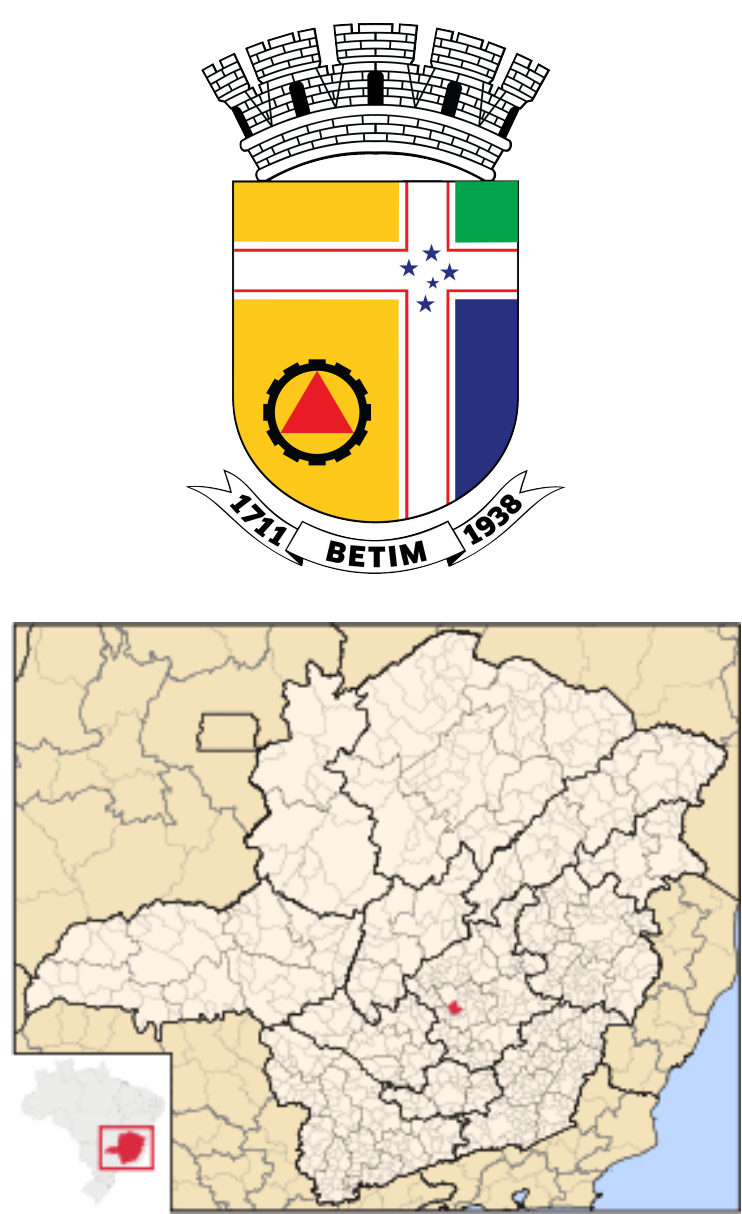

Fonte: http://www.camarabetim.mg.gov.br/simbolos.

Acesso 18.setembro.2016

1 Docente no Centro Universitário UNA; Mestre em Ciências Sociais pela PUC Minas; Especialista em Marketing Político pela UFMG; Bacharel em Ciências Sociais. Endereço eletrônico: jurutan.alves@yahoo.com.br 


\section{A luta por Betim}

Jurutan Alves da Silva

Este texto visa mostrar quais famílias disputam o poder executivo no município de Betim em Minas Gerais nas eleições municipais deste ano. As estratégias utilizadas pelos protagonistas políticos, em muitos casos, são expostas no texto.

Na primeira parte do texto é apresentado o município de Betim e sua história. Desde o momento de distribuição das terras em sesmarias até o desenvolvimento industrial. 0 crescimento eleitoral e a disputa nas eleições também estão inclusas.

Já a segunda parte menciona sobre os 11 candidatos que disputam o pleito no município. Suas histórias e as de suas famílias são descritas. Há candidato que disputa as eleições em Betim e é naturalizado, outros são brasileiros de regiões diferentes no estado de Minas Gerais e até de outros estados da federação.

Na última parte do artigo são apresentadas as considerações finais. Alguns candidatos disputam a eleição municipal para apresentar seu nome no município e avaliarem uma possível candidatura a vereador nas próximas eleições. Outros já possuem experiência na disputa eleitoral e tem recursos próprios para investirem na campanha política. Essas questões e suas conseqüências no jogo político municipal são apresentadas.

\section{1 - 0 alvorecer}

Betim é uma cidade localizada na região metropolitana de Belo Horizonte no estado de Minas Gerais, sito a mais ou menos 33 quilômetros da capital mineira. Sua origem remota aos tempos dos Bandeirantes quando no século XVIII Joseph Rodrigues Betim, que era cunhado do bandeirante Fernão Dias Paes Leme, recebe a Carta de Sesmaria referente às terras localizadas no vale do Ribeirão da Cachoeira (Rio Betim), que até aquele momento pertenciam ao território da primitiva Vila Real de Sabará. 
Durante o ano de 1890 houve uma reforma político-administrativa devido a Constituição que alterou a situação territorial no estado de Minas Gerais. Neste período Esmeraldas foi desmembrado de Sabará e durante o ano de 1901, elevado à condição de município. Capela Nova de Betim (como era conhecido o povoado) passou então a integrar este território.

Comemorando a data de 7 de setembro de 1923, foi criado o distrito de Betim com sede no povoado de mesmo nome, mas ainda integrando o território de Santa Quitéria e em 17 de dezembro de 1938 devido ao decreto de número 148 do então governador do estado de Minas Gerais Benedito Valladares Ribeiro o distrito é elevado a município.

Até os anos de 1940 a economia do município era baseada na agropecuária. No final dessa década começa a surgirem às primeiras indústrias. Durante a década de 1960, com a inauguração da rodovia Fernão Dias que corta o município e liga os estados do Espírito Santo, Minas Gerais e São Paulo a economia do município torna-se basicamente industrial.

O município de Betim tem estimado, segundo o Instituto de Geografia e Estatística (IBGE), hoje uma população de 417307 habitantes destes 278234 são eleitores. Neste caso, devido à legislação eleitoral em vigor, as eleições municipais podem ocorrer em dois turnos, caso nenhum candidato consiga no primeiro turno das eleições 50\% mais 1 voto dos considerados válidos.

Nas eleições deste ano irão concorrer ao pleito para prefeito 11 candidatos e para vereador 539. São 23 vagas para o cargo de vereador o que faz com que tenha a proporção 23,43 candidatos/vaga. Neste artigo, vamos nos ater apenas aos candidatos ao cargo de prefeito.

\section{2 - Os guerreiros}

No Brasil estar inserido em um grupo familiar que possui acesso aos mecanismos políticos ajuda o candidato ao pleito público a alcançar suas ambições nessa área. 0 sobrenome favorece ao candidato que pretende participar de um pleito eleitoral. A família, segundo Bezerra (1995), é uma instituição de muita importância na organização da sociedade e da política do Brasil. Para Nunes (2003) os brasileiros se referem à família de forma extensa, 
ou seja, à parentela. Quando o brasileiro deseja informar sobre sua família nuclear este diz minha mulher e filhos. Bezerra (1995) diz que o favorecimento dos parentes nas relações em geral não é vista por estes como sendo algo negativo. 0 beneficiado e o beneficiador podem ver essa relação como um dever cumprido para com aqueles que pertencem ao grupo familiar e precisam de alguma ajuda.

O grupo familiar pode decidir até a que ponto um candidato poderá ou não chegar. Não é incomum encontrar candidatos a cargos eletivos sendo apoiado por entes familiares no país. Os conchavos políticos para que o poder permaneça nas mãos de pessoas integrantes das famílias é normal de acontecer. Redes com ligações pessoais entre os integrantes, trocas de favores, nepotismo e o clientelismo-familiar são ações que fazem parte do jogo para manter o status quo nas mãos de famílias que comandam o jogo político em determinadas regiões do país.

Em Betim não é diferente das demais regiões do Brasil. Serão apresentados os candidatos, e suas respectivas histórias e ligações familiares, que estão disputando o cargo eletivo para prefeito no município.

\section{1 - Os Medioli}

Um dos candidatos à prefeitura de Betim é Vittório Medioli, nascido na Itália e naturalizado brasileiro, dono das empresas: Sempre Editora que publica os jornais O Tempo um dos principais do estado de Minas Gerais - e Super o mais vendido no Brasil (presente em 400 municípios mineiros, sendo distribuído gratuitamente em alguns); do grupo SADA (transportes e armazenagens); OMR componentes automotivos; Eber Bio-Energia; também de concessionárias de veículos e caminhões; fundou o time de vôlei SADA que associou ao Cruzeiro (clube de futebol em Minas Gerais) e surgiu o Sada Cruzeiro hoje um dos maiores clubes de vôlei do país. Foi eleito deputado federal em quatro legislaturas, entre os anos de 1991e 2007, filiado ao PSDB (Partido da Social Democracia do Brasil). Para concorrer à prefeitura betinense, filiou-se ao PHS (Partido Humanista da Solidariedade). A coligação intitulada "O Bem de Betim" conta com os partidos PP / DEM / PTN / PR / PHS / PMN / PV / PMB / PTC / PSDB / PC do B / PT do B / PRB / SD / PSD. Essa coligação possui partidos considerados de esquerda como o PT do B e PC do B passando pelo centro e chegando aos 
partidos que estão caminhando para a extrema direita como o DEM e PSDB. O limite de gasto fornecido para a campanha é de $\mathrm{R} \$ 4.524 .655,00$ deste total, $\mathrm{R} \$ 1.500 .000,00$ são de recursos próprios.

A família de Vittório Medioli é oriunda do norte da Itália e seus investimentos foram realizados principalmente em moinhos de trigo na região da Emília-Romanha. É filho do meio de Anna e Ricardo Medioli, seu bisavô Vincenzo Medioli foi responsável pela distribuição de energia elétrica na cidade de Parma em 1888, construindo uma hidrelétrica no rio Taro. Vittório Medioli nasceu nessa cidade e chega ao Brasil em 1976, naturaliza em 1981.

\section{2 - Santos}

Pelo PT (Partido dos Trabalhadores) concorre ao pleito de prefeito no município na denominada chapa pura (sem nenhuma coligação com outros partidos políticos) Eutair Antonio dos Santos, 52 anos, natural Pedra do Indaiá em Minas Gerais, vereador no município pela quarta legislação seguida. A mensagem é de renovação. A estrela vermelha símbolo do PT foi retirada das mídias e propagandas políticas. Essa renovação é devido à situação em que o partido permaneceu após ser vinculado pela mídia nacional a casos de corrupção.

Seus pais são Waltuir José dos Santos e Ione Ferreira dos Santos. Pedra do Indaiá, sua cidade natal, é considerada um município de pequeno porte com uma população estimada de 4028 habitantes. Formado em Filosofia e direito pela Pontifícia Universidade Católica chega em Betim no ano de 1990 com o intuito de lecionar história em uma escola do município. Sua trajetória política passa pelo movimento estudantil; torna-se assessor da Secretaria de Governo no período entre julho e dezembro de 1993; diretor escolar de 1994 a 1998; secretário municipal de Educação e Cultura entre 1999 e 2000; é eleito vereador no município e exerce seu mandato durante quatro legislaturas seguidas.

\section{3 - Pinho}

O candidato do PMDB (Partido do Movimento Democrático Brasileiro) é Ivair Nogueira do Pinho, natural do próprio município onde nasceu em 1951, foi prefeito no período de 1991 a 1992 devido à morte do prefeito eleito em 1989 - Osvaldo Resende Franco - que faleceu em um acidente de avião no ano de 1991; foi eleito deputado estadual em 1995 e está em sua sexta legislatura. Seu partido para concorrer ao pleito municipal fez coligação com o PDT 
(Partido Democrático Trabalhista), PTB (Partido trabalhista Brasileiro) e com o PROS (Partido Republicano da Ordem Nacional). Até o momento Pinho está investido de seus recursos próprios R \$ 500.000,00 na campanha eleitoral.

Seus pais Rubens do Pinho Ângelo e Maria Madalena Nogueira nasceram em faleceram em Betim. Sua mãe era conhecida como dona Marieta e era doméstica, já seu pai era influente na vida política local, mesmo não disputando nenhum cargo eletivo. Também foi comerciante sendo proprietário de um armazém. Rubens do Pinho Ângelo e Maria Madalena Nogueira são filhos de betinenses e herdaram a fazenda que pertenceu a seus bisavôs que localizava em uma região onde hoje é a colônia Santa Isabel no bairro Citrolândia. A família Nogueira é proveniente da região norte de Betim, área da Serra Negra/Várzea das flores.

\section{4 - Abreu}

O PPS (Partido Popular Socialista), sem fazer coligações com outros partidos, tem como candidato à prefeitura municipal de Betim Welinton Sandro de Abreu (conhecido pela alcunha de Welinton Sapão), natural de São José do Goiabal - município com população estimada em 5653 habitantes, segundo o Instituto de Geografia e Estatística (IBGE) - ensino médio, vereador pela segunda legislatura no município de Betim assumindo o cargo em 2009 quando o vereador Marcos Siqueira filiado ao PP (Partido Progressista) acusado por propaganda extemporânea foi cassado pelo Tribunal Regional Eleitoral do município, nessa época Sapão também era filiado ao PP - comerciante. Seus progenitores são: Paulo Antônio Abreu e Maria das Graças Abreu.

Em 2012 Welinton Sandro de Abreu filiado ao PSB (Partido Socialista Brasileiro) obteve a maior votação da história de Betim em um vereador 5787 votos. Seu suplente na câmara municipal Raimundo Antônio José Salomão filiado ao PR (Partido da Renovação) o acusou para o Ministério Público de usar uma ONG (Organização Não Governamental) para conseguir estes votos. A ONG teria recebido da prefeitura municipal $\mathrm{R} \$ 3.000 .000,00$ e comprado materiais com preços superfaturado. 0 inquérito transcorre em segredo de justiça e até o momento não houve sentença. Em 2012, Abreu concorre ao pleito para uma vaga na Assembleia Legislativa de Minas Gerais e obtém 29659 votos.

\section{5 - Carvalho}


A coligação "com a força do povo" que une os partidos PSDC (Partido Social Democrata Cristão) e PPL (Partido Pátria Livre) concorre ao pleito do município com Carlos Roberto de Carvalho, mais conhecido por Beto do Depósito. Natural de Nova Era em Minas Gerais município de pequeno porte com uma população estimada em 17996 habitantes comerciante. Inicia sua trajetória política na câmara municipal como vereador eleito em 1996 pelo PPB (Partido Progressista Brasileiro), retorna em 2004 pelo PPS (Partido popular Socialista) e em 2012 é eleito novamente para seu terceiro mandato pelo PSC (Partido Social Cristão). Filho de Francisco Pinto de Carvalho e de Maria Zilá de Carvalho.

\section{6 - Silva}

O PSC (Partido Social Cristão) concorre ao cargo máximo da prefeitura de Betim com o candidato mais novo na disputa eleitoral Erasmo Carlos Oliveira da Silva, 38 anos, natural de Brumado no estado da Bahia - município com 69473 habitantes - feirante, filho de Manuel Joaquim da Silva e Ivani Oliveira da Silva, começou sua vida política em 2012 e está em seu primeiro mandato como vereador no município, sendo eleito filiado ao PDT (Partido democrático Trabalhista), vive em Betim há 32 anos.

\section{7 - Ribeiro}

Maria das Dores Ribeiro, mais conhecida por Dorinha, concorre à prefeitura pelo PSTU (Partido Socialista dos Trabalhadores Unificado), tem 50 anos, natural de Ubaporanga em Minas Gerais - município com população estimada em 12591 habitantes - servidora pública municipal. É a primeira vez que concorre em uma eleição.

\section{8 - Moura}

A coligação “Acorda Betim" liderada pelo PSB (Partido Socialista Brasileiro) em coligação PEN (Partido Ecológico Nacional) e REDE concorre com o candidato Wenceslau Alvares Francisco de Moura, 51 anos, natural de Sete Lagoas em Minas Gerais - município com a estimativa de 234221 habitantes - filho de Walter Franscisco de Moura e Maria Helena Álvares de Moura, empresário na área da engenharia civil. É a primeira vez que concorre em uma eleição.

\section{9 - Sousa}


O PSOL (Partido Socialismo e Liberdade) com chapa única concorre à prefeitura betinense com o candidato Wilson Ribeiro de Sousa, 49 anos, advogado, natural de Teófilo Otoni em Minas Gerais - município com 141502 habitantes em estimativa - filiação: Miguel Teles de Sousa e Eva Ribeiro de Sousa. Concorre pela primeira vez em uma eleição.

\subsection{Parreira}

Fernando da Mendonça Parreira filiado ao PSL (Partido Social Liberal) é o candidato escolhido para disputar a eleição em chapa única pelo partido. Natural de Belo Horizonte capital mineira, 62 anos, filho de Teotônio Parreira Coelho e Rosa Maria de Jesus dos Santos, foi candidato na eleição de 2008 para o cargo de vereador e obteve 427 não sendo eleito.

\subsection{Bernardes}

O PCB (Partido comunista Brasileiro) está na disputa municipal como chapa única e com o candidato José Augusto Bernardes, 66 anos, filho de Jose Bernardes De Oliveira e Maria Rosa De Oliveira, natural de Itauna em Minas Gerais - município com aproximadamente 92091 habitantes - aposentado. Em 2008 concorreu ao pleito para vereador pelo PSOL e não foi eleito, no ano de 2014 concorreu nas eleições para o cargo de deputado estadual também não sendo eleito.

\section{Considerações finais}

Segundo pesquisa realizada pelo instituto Paraná Pesquisas os principais candidatos com chances de irem para o segundo turno das eleições em Betim são: Vittório Medioli e Ivair Nogueira. Não por acaso dois candidatos com histórico familiares de pessoas envolvidas em administração de empresas e também na política em suas regiões de habitação. São também os dois candidatos que mais possuem recursos para investirem nas campanhas eleitorais.

Há candidatos que disputam o pleito pela primeira vez e em partidos considerados pequenos, ou seja, sem maiores representatividades diante dos eleitores. Neste caso, tentam divulgar as ideologias de seus partidos aproveitando o pleito e também conhecerem suas capacidades de obtenção de votos para uma próxima eleição. As chances de conseguirem chegar a um eventual segundo turno são mínimas. 
O PT é um caso à parte na disputa em Betim. 0 partido já elegeu prefeito em outras duas legislaturas: Maria do Carmo Lara Perpétuo administrou o município de 1993 a 1996 e Jésus Mário de Almeida Lima de 1997 a 2000. Durante seu mandato, Lima sofreu uma tentativa de assassinato em 1997. 0 então prefeito de Betim foi atingido com cinco tiros e permaneceu 39 dias internado no hospital regional de Betim. José do Nascimento Elias, exvereador e ex-presidente da Câmara Municipal de Betim foi condenado como sendo o mandante do crime. Após este período no governo o partido não retornou ao poder do município. Atualmente, segundo pesquisas realizadas pelo instituto Paraná Pesquisas o partido possui $4,2 \%$ das intenções de votos na eleição. Boa parte deste desgaste se dá ao fato do partido político estar associado a casos de corrupção política noticiada pela imprensa: como o Mensalão - caso em que deputados federais foram comprados para aprovar projetos de lei do governo federal - e do Petrolão - desvios na empresa de petróleo (PETROBRAS) com o fim de manter o partido no poder federal. Ambos os casos foram noticiados pela imprensa nacional atingindo a imagem do partido político. Houve também a destituição da presidente da república Dilma Vana Roussef filiada ao partido político dos trabalhadores neste ano. A imagem do partido foi associada à corrupção. Este fato ajuda a explicar o baixo índice de votos destinado ao candidato petista.

\section{Referências:}

Marcos Siqueira cassado pela justiça. O Tempo. 12 de setembro de 2009. Disponível em $<$ www.otempo.com.br/capa/pol\%C3\%ADtica/marcos-siqueira-\%C3\%A9-cassado-pelajusti\%C3\%A7a-eleitoral-de-betim-1.241820 > Acesso em 12/09/16

Justiça condena 2 por tentar matar prefeito de Betim. Folha on Line. 26 de junho de 1998. Disponível em < $\underline{w w w 1 . f o l h a . u o l . c o m . b r / f o l / g e r a l / u l t 260698148 . h t m>~ A c e s s o ~ e m ~ 12 / 09 / 16 . ~}$

Pesquisa traz PHS na frente em Betim. O Tempo. 2 de setembro de 2016. Disponível em: <www.otempo.com.br/hotsites/elei\%C3\%A7\%C3\%B5es-2016antigo/pesquisa-traz-phs-nafrente-em-betim-1.1364656> Acesso em 12/09/16. 
BEZERRA, Marcos Otávio. Relações e redes pessoais. In: BEZERRA, Marcos Otávio. Corrupção: um estudo sobre poder público e relações pessoais no Brasil. Rio de janeiro: ANPOCS, 1995.

eutair.com.br/index.php/perfil . Acesso em 12/09/16.

GRANBEL, História de Betim. 27 de janeiro de 2011. Disponível em: <www.granbel.com.br/index.php/municipios-metropolitanos/80-municipio-de-betimmunicipio-de-betim/105-historia-de-betimmg.html> Acesso em 12/09/16.

MEDIOLI, Vittório.

em $<$ www.facebook.com/vittoriomedioli/about/?entry point=page nav about item\&tab=page in fo $>$ Acesso em 12/09/16.

NUNES, Edson. A construção do insulamento burocrático e do corporativismo e a nacionalização do clientelismo. In: NUNES, Edson. A gramática política no Brasil: clientelismo e insulamento burocrático. Rio de Janeiro: Zahar, 2003.

NUNES, Edson. Tipos de capitalismo, instituições e ação social. In: NUNES, Edson. A gramática política no Brasil: clientelismo e insulamento burocrático. Rio de Janeiro: Zahar, 2003.

PAVANELLI, Lucas. Vereador acusado de desvio de recursos. 0 Tempo. 14 de agosto de 2014. Disponível em <www.otempo.com.br/o-tempo-betim/vereador-\%C3\%A9-acusado-dedesvio-de-recurso-p\%C3\%BAblico-1.900214> Acesso em 12/09/16

PAVANELLI, Lucas. Vereador é acusado de desvio de recurso público. O Tempo. 14 de agosto de 2014. Disponível em <www.otempo.com.br/o-tempo-betim/vereador-\%C3\%A9acusado-de-desvio-de-recurso-p\%C3\%BAblico-1.900214 pesquisado em 12/09/16> Acesso em 12/09/16.

PINHO, Ivair $\quad$ Nogueira do. disponível em $<$ www.facebook.com/IvairNogueiradoPinho/about/?entry point=page nav about item \&tab= page_info $>$ Acesso em 12/09/16.

PINHO, Ivair Nogueira. Disponível em <www.ivairnogueira.com.br/2016/\#quem-somos> Acesso em 12/09/16. 
SANTOS, Eutair Antônio dos. Disponível em $<$ www.facebook.com/EutairSantosonline/about/?entry point=page nav about item\&tab=pa ge info > Acesso em 12/09/16. 